\title{
Do different clinical evidence bases lead to discordant health-technology assessment decisions? An in-depth case series across three jurisdictions
}

\author{
This article was published in the following Dove Press journal: \\ ClinicoEconomics and Outcomes Research \\ 29 January 2013 \\ Number of times this article has been viewed
}

\author{
Daryl S Spinner' \\ Julie Birt ${ }^{2}$ \\ Jeffrey W Walter' \\ Lee Bowman ${ }^{2}$ \\ Josephine Mauskopf' \\ Michael F Drummond ${ }^{3}$ \\ Catherine Copley- \\ Merriman \\ 'RTI Health Solutions, Research \\ Triangle Park, NC, USA; ${ }^{2}$ Eli Lilly and \\ Company, Indianapolis, IN, United \\ States; ${ }^{3}$ University of York, York, UK
}

\begin{abstract}
Background: Health-technology assessment (HTA) plays an important role in informing drug-reimbursement decision-making in many countries. HTA processes for the Pharmaceutical Benefits Advisory Committee (PBAC) in Australia, the Common Drug Review (CDR) in Canada, and the National Institute for Health and Clinical Excellence (NICE) in England and Wales are among the most established in the world. In this study, we performed nine in-depth case studies to assess whether different clinical evidence bases may have influenced listing recommendations made by PBAC, CDR, and NICE.

Methods: Nine drugs were selected for which the three agencies had provided listing recommendations for the same indication between 2007 and 2010. We reviewed the evidence considered for each listing recommendation, identified the similarities and differences among the clinical evidence bases considered, and evaluated the extent to which different clinical evidence bases could have contributed to different decisions based on HTA body comments and public assessment of the evidence.

Results: HTA agencies reached the same recommendation for reimbursement (recommended for listing) for four drugs and different recommendations for five drugs. In all cases, each agency used different evidence bases in their recommendations. The agencies considered overlapping sets of clinical comparators and trials when evaluating the same drug. While PBAC and NICE considered indirect and/or mixed-treatment comparisons, CDR did not. In some cases, CDR and/or NICE excluded trials from review if the drug and/or the comparator were not administered according to the relevant marketing authorization.

Conclusions: In the listing recommendations reviewed, considerable variability exists in the clinical evidence considered by PBAC, CDR, and NICE for drug-listing recommendations. Differences in evidence resulted from differences in the consideration of indirect and mixedtreatment comparison data and differences in medical practice in each jurisdiction.
\end{abstract}

Keywords: health-technology assessment, reimbursement decisions, evidence

\section{Introduction}

Health-technology assessment (HTA) plays an important role in informing clinical guidance and health-care reimbursement decisions in many countries. ${ }^{1-4}$ HTA agencies for major jurisdictions and their specific drug-technology appraisal processes (eg, the Pharmaceutical Benefits Advisory Committee [PBAC] in Australia, the Common Drug Review [CDR] in Canada, and the National Institute for Health and Clinical Excellence [NICE] in England and Wales) have been established to evaluate clinical
Correspondence: Julie Birt Global Health Outcomes, Eli Lilly and Company, Drop Code 1730, Indianapolis, IN 46285, USA

Tel +l 3172773644

Email birt_julie@lilly.com 
and economic evidence, provide recommendations on drug reimbursement and formulary listing, ${ }^{5-7}$ and serve as models for HTA across the globe.

Evidence collected for HTA submissions by drug manufacturers is usually based on guidelines provided by the HTA bodies. Most HTA agencies require the systematic collection of relevant clinical and economic evidence to support drug submissions. ${ }^{7}$ However, written guidelines from these HTA bodies vary with regard to how studies should be selected for inclusion and assessed, thus different (although generally overlapping) bodies of evidence are likely to be generated for each jurisdiction. ${ }^{8}$

Previous research has described disparate evidence bases for the same drug across HTA jurisdictions. Clement and colleagues ${ }^{3}$ evaluated the overall rates of positive and negative listing recommendations made by PBAC, CDR, and NICE through December 31, 2008, and presented case studies for three drugs that had each been reviewed by all three agencies. They found variable reimbursement recommendations across the agencies for the three drugs reviewed and speculated as to reasons for differences, including the differences in overall types of clinical and economic evidence considered, although the authors did not describe in detail the evidence considered by each agency in reaching their decisions. ${ }^{3}$ Trueman and colleagues ${ }^{9}$ evaluated HTA decisions for drug-eluting stents across four jurisdictions to determine the extent to which the assessment methods, evidence considered, and resulting recommendations diverged. The authors found considerable variability across agencies in the number of trials and types of trials (randomized versus nonrandomized) considered, clinical end points considered, how the data were quantitatively assessed, and conclusions drawn based on the clinical evidence. Although the clinical evidence base is just one factor taken into consideration in the HTA decision-making process (others being national and regional differences in drug costs, currently available treatments, and priorities and values of the populations affected), ${ }^{4,5,10-12}$ the clinical evidence base is a key building block that is relevant and transferable across all geographies. ${ }^{7}$

A recent study by Rocchi and colleagues ${ }^{4}$ focusing on drug-listing recommendations by CDR suggested that clinical evidence may be more important than economic evidence in CDR decision-making. In the current paper, we add to the existing literature describing evidence-based HTA decisions by presenting an in-depth and detailed analysis of clinical evidence bases considered by three HTA agencies (PBAC, CDR, and NICE) for each of nine drugs/indications. Further, we sought to gain insight into how divergence in clinical evidence may impact agency listing recommendations, and to understand factors contributing to divergence in clinical evidence bases used in developing these recommendations. These three agencies were selected for the analysis because their HTA processes are among the most transparent and refined: they serve as models for other countries, provide detailed guidelines for identifying the clinical evidence, and provide publicly available information on reimbursement decisions. Further, these agencies were chosen for our analysis to add to the existing information about HTA decisions and the processes underlying them for these agencies. ${ }^{2,3,8}$

\section{Methods}

\section{Selection of drugs/disease indications}

We selected drugs for which PBAC, CDR, and NICE had each provided reimbursement recommendations for the same indications between 2007 and 2010. We began with a list of 210 HTA drug decisions published by PBAC between 2005 and 2010. Decisions by the CDR were available for 86 of those drugs, and decisions by NICE were available for 36 of those 86 . Of the 36 drugs for which decisions were available from all three agencies, 20 drugs had decisions published between 2007 and 2010. To increase the likelihood that similar clinical evidence had been available for all three drugs at the time the decision was made, we further refined our list to include only those drugs for which the three agency decisions were issued within 15 months of one another. When multiple decisions matching these criteria existed for a particular drug-indication combination for a given agency, the first such decision was chosen for inclusion in the analysis to enable comparison of decisions based on the existing body of data without changing recommendations over time based on other external factors (pricing negotiations between the HTA body and the manufacturer). This process yielded a final list of nine drugs/indications for consideration (Table 1). For eight of the nine drugs, recommendations by all three agencies were issued within an 11-month period; for the remaining drug, recommendations were issued within a 14-month period. Overall, the average period separating earliest and latest recommendations issued was 7.2 months (median 7.1 months, range 1-14 months).

\section{Extraction of HTA decision data}

The published HTA decisions by the three agency drugreview programs for each of nine drugs/indications were reviewed, including Canadian Expert Drug Advisory Committee final recommendation documents from CDR, Technology Appraisal Guidance documents from NICE, and 


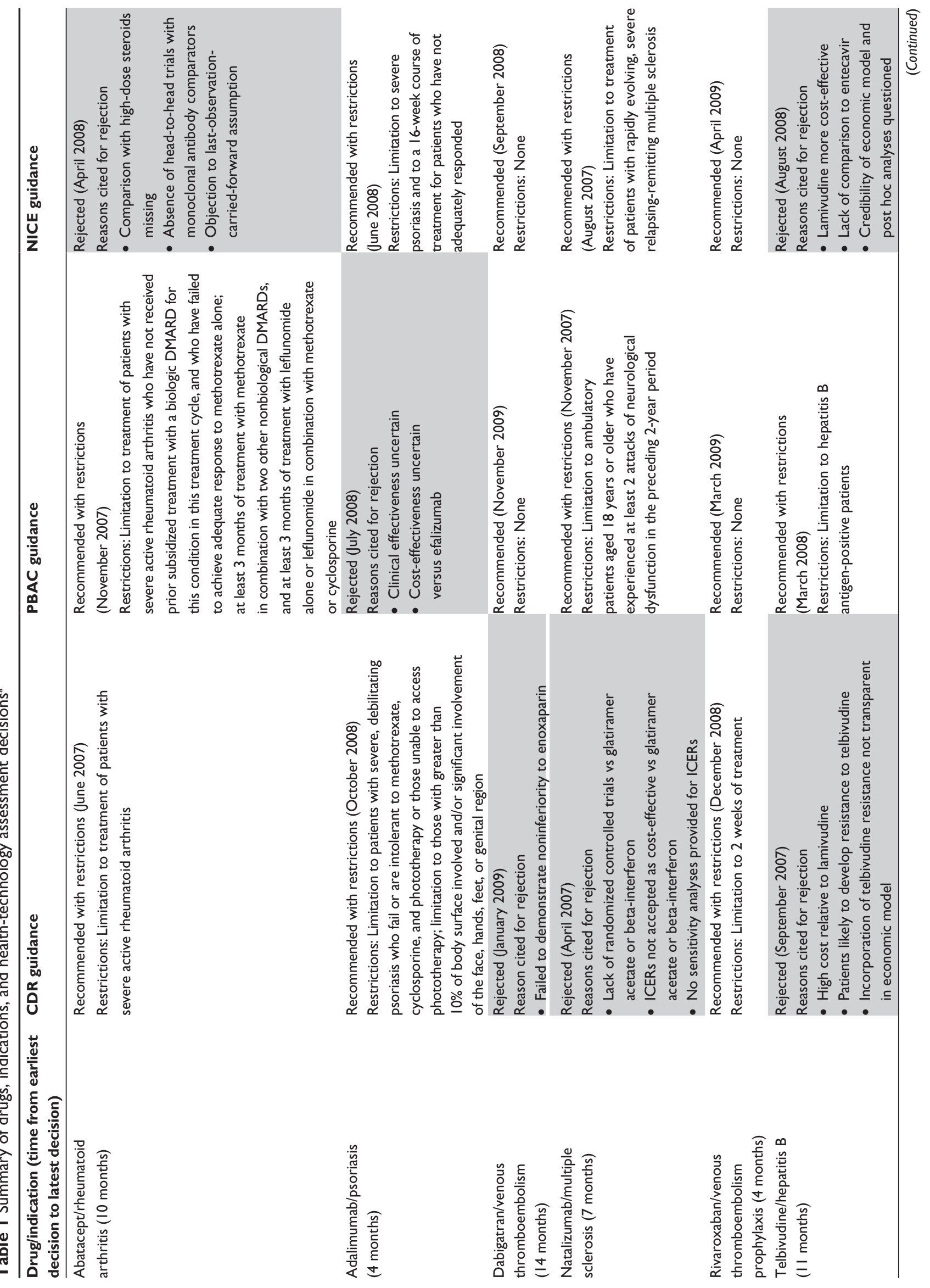


Public Summary Documents from PBAC. For the review of recommendations from NICE, when insufficient information regarding clinical data used was available in the Technology Appraisal Guidance document, the manufacturer's submission and/or the Evidence Review Group (ERG) report were reviewed to collect more detail. PBAC and CDR did not have equivalent source documents; therefore, we were limited to their respective final recommendations and Public Summary Documents for our analysis.

The agency decisions to recommend or reject reimbursement were noted, along with any reported restrictions, and (when available) the stated rationale for agency decisions to reject listing of the drug (Table 1). For the purpose of this study, agency restrictions were considered as such only if they were more limiting than the drug's marketing authorization by the relevant regulatory agency (ie, Therapeutic Goods Administration [Australia], Health Canada, European Medicines Agency, or Medicines and Healthcare Products Regulatory Agency [UK]) (drug-marketing authorizations relevant to each HTA agency are reviewed in Table S1). The licensing approval source documents were reviewed if the marketing authorization was not explicitly described in the HTA documents, which occurred exclusively for CDR-relevant marketing authorizations from Health Canada.

Recommendation of reimbursement system-specific restrictions, such as those requiring prescription by a physician specialist, those with authority required for reimbursement, and those with supply/quantity limits, were not considered restrictions for this study, because they did not generally directly relate to the evidence base used in the agency decision-making process. Examples of restrictions considered included those related to limitation of use of drug to subsets of patients based on disease severity, failure of previous treatments, and/or other specific criteria narrowing the eligible patient population. Our analysis included an assessment of clinical data supporting each decision, which were extracted from the reviewed documents, including comparator agents considered by each agency, numbers of and the specific clinical trials included and their study designs (eg, randomized controlled trial [RCT], non-RCT/ observational study), and the nature of drug comparisons (direct [head-to-head] or indirect/mixed treatment [eg, metaanalysis]) considered. Clinical data supporting each decision were extracted from the reviewed documents, including the comparator agents considered by each agency, the specific trials submitted, and study designs (eg, RCT, non-RCT/ observational study, meta-analysis). 


\section{Results}

Table 1 summarizes reimbursement recommendations (and, if applicable, any restrictions) reached by PBAC, CDR, and NICE for the nine drugs/indications evaluated, along with the agency rationale for rejecting any drugs. Four of the nine drugs (rivaroxaban, tenofovir, ustekinumab, and varenicline) were recommended for reimbursement by all three HTA agencies, although some were recommended with restrictions (Table 2). The only drug with the exact same recommendation across all three agencies (recommended with restrictions) was varenicline. Five of the nine drugs/indications (abatacept, adalimumab, dabigatran, natalizumab, and telbivudine) received dissimilar decisions across the three agencies, with at least one agency opting to reject reimbursement (Table 2). In no cases were all three agencies in agreement to reject a drug, and in only one case (ie, telbivudine) did two agencies reject the same drug for reimbursement.

\section{Agency consideration of clinical trials}

The complete set of direct and indirect clinical trials used as the evidence base by the three agencies in informing the drugreimbursement recommendations was different in most cases, often related to which comparators were considered relevant in each geography. Across the nine drugs reviewed, agencies considered different numbers of direct head-to-head trials, with CDR considering 30\% more trials (35) than the agency with the next-highest number of head-to-head trials (NICE 27, PBAC 25). In no cases were the exact same number of total trials considered across all agencies, and in some cases the total number of trials (for both direct and indirect comparison) considered across agencies differed widely. For example, for tenofovir, CDR evaluated two RCTs, PBAC five, and NICE 25, whereas for varenicline, PBAC evaluated two RCTs, CDR eight, and NICE 90. However, even when the same direct comparator was used by all three agencies, different numbers of trials were included in the evidence base. For example, enoxaparin was considered as the direct comparator for rivaroxaban by all three agencies, and the PBAC evidence base included three RCTs for enoxaparin, whereas CDR included five and NICE included seven. Likewise, for varenicline, bupropion and placebo were considered the direct comparators across all agencies, and PBAC included two trials, NICE included three, and CDR included eight. In only two cases (adalimumab and ustekinumab) did all three agencies clearly report considering an identical set of direct comparison trials, with adalimumab being recommended for reimbursement by two of the agencies, and ustekinumab by all three. In addition to what comparators were considered relevant, the variability in clinical evidence considered was most often related to selective HTA agency decisions to include or exclude specific trials, as evident in the following examples.

\section{Choice of comparator}

\section{Abatacept}

For direct comparison, PBAC considered the main trial against placebo and infliximab (ATTEST), whereas NICE did not, because the patients included in the trial did not reflect the licensed indication for abatacept (ie, they had not failed on prior antitumor necrosis-factor treatment). For indirect and/or mixed-treatment comparison evidence, NICE considered additional comparators that PBAC did not, including rituximab, adalimumab, certolizumab, etanercept, and golimumab. NICE also noted that for some patients, abatacept would be used as a last line of therapy for which high-dose corticosteroids would be a relevant comparator, but the manufacturer did not provide data comparing abatacept to high-dose corticosteroids.

\section{Adalimumab}

NICE considered additional indirect/mixed-treatment comparisons against etanercept, cyclosporine, and methotrexate that were not included by PBAC.

\section{Dabigatran}

PBAC considered indirect/mixed-treatment comparisons against rivaroxaban, whereas the manufacturer submission to NICE did not mention any rivaroxaban RCTs, nor was this comparator mentioned in the NICE ERG report. This discrepancy was likely because NICE had not yet issued a decision on rivaroxaban, which was issued 7 months later and thus had not yet been recommended, whereas PBAC had issued a positive listing on rivaroxaban 8 months before its decision on dabigatran. NICE also considered indirect/ mixed-treatment comparison to fondaparinux, which PBAC did not.

\section{Ustekinumab}

PBAC and NICE considered indirect comparison to etanercept, adalimumab, and infliximab. NICE also considered indirect/mixed-treatment comparison against efalizumab, which PBAC did not.

\section{Varenicline}

NICE was the only agency that considered direct or indirect/ mixed-treatment comparison of varenicline against nicotinereplacement therapy. 


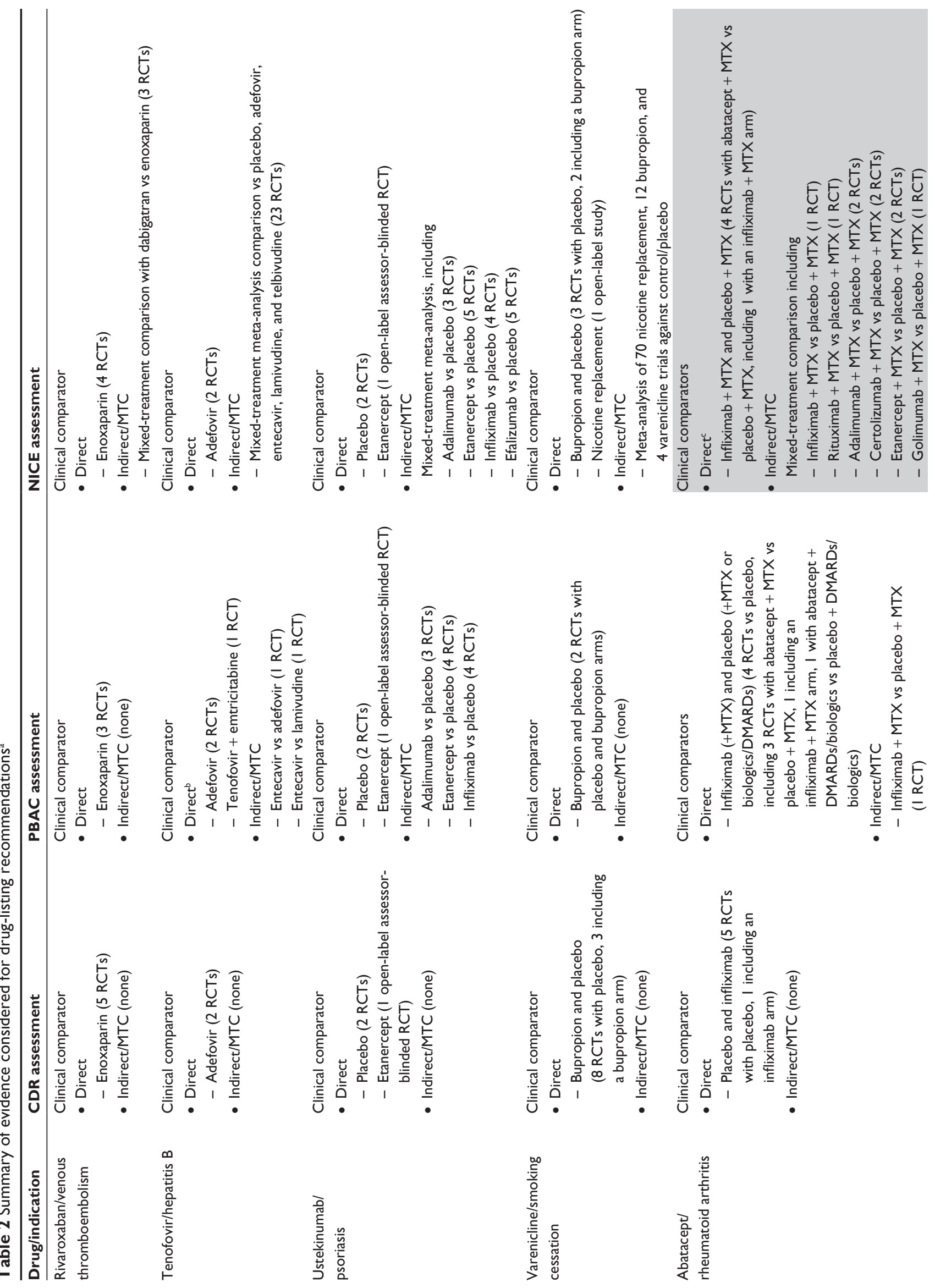




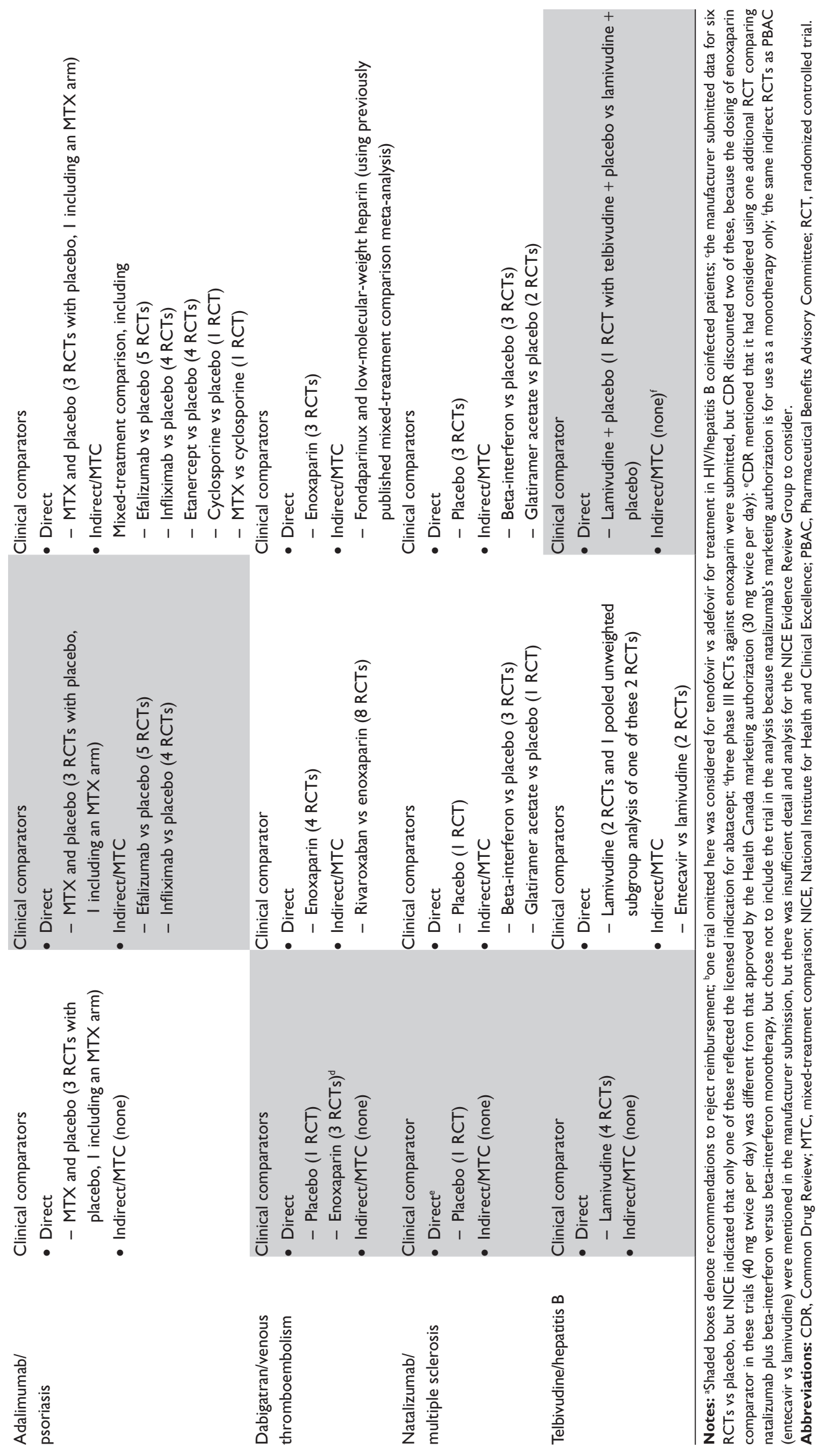




\section{Selective agency decision}

\section{Abatacept}

The manufacturer's submission to NICE presented six RCTs comparing abatacept to placebo, but NICE discounted all but one of these (ATTAIN), because five of the trials did not reflect the licensed indication for abatacept with regard to use after failure of a tumor necrosis-factor inhibitor and/or at its licensed dose.

\section{Dabigatran}

Of the three phase III clinical trials identified by CDR, two were ultimately excluded from consideration because the dosing of the enoxaparin comparator was different from that outlined in the relevant marketing authorization. The lack of inclusion of these other trials may have been a major contributor to CDR's rejection of dabigatran, because the agency specifically mentioned that the only phase III trial considered in the assessment (REMOBILIZE) did not demonstrate noninferiority against the enoxaparin comparator. CDR was the only agency that rejected dabigatran for listing.

\section{Natalizumab}

All three agencies considered the same direct phase III clinical trial (AFFIRM), but the NICE submission included two additional phase II studies. CDR excluded from consideration one RCT that compared natalizumab plus beta-interferon versus beta-interferon alone because natalizumab was licensed for use only as a monotherapy.

\section{Rivaroxaban}

PBAC, CDR, and NICE considered a core set of three direct head-to-head trials (RECORD 1, RECORD 2, and RECORD 3), but NICE considered an additional trial (total of four trials considered), and CDR considered two additional trials (total of five trials considered). CDR and NICE both considered the additional phase III RECORD 4 trial, which was not part of the manufacturer submission to PBAC nor identified by PBAC in its literature search due to timing.

\section{Telbivudine}

A common pivotal study (the GLOBE trial) was considered by all three agencies. The manufacturer's submissions to PBAC and NICE also included an additional trial with all Chinese patients, which was not considered by CDR. The manufacturer submission to NICE identified three trials in addition to GLOBE $(015,018$, and 019), but the GLOBE trial was the only one analyzed by the manufacturer in detail. Therefore, NICE was unable to consider the other three trials in the evaluation.

\section{Ustekinumab}

Although the same set of three trials was considered by PBAC and NICE for this comparison, the submission to NICE included an additional phase III trial published in 2006 that should have been available to PBAC, but was either not identified by the agency, not present in the manufacturer submission, or excluded from the PBAC assessment for another reason.

\section{Agency consideration of direct- and indirect-comparison evidence}

Agency submission guidelines clearly indicate that both direct head-to-head trial data (ie, trials that include the drug being evaluated) and indirect- and mixed-treatment comparison data are accepted and considered in the assessment of new drugs. However, based on the nine drugs/indications reviewed, PBAC reported considering indirect or mixedtreatment evidence in seven of nine decisions (78\%). NICE considered indirect or mixed-treatment evidence in eight of nine $(89 \%)$ decisions; in the one case in which indirect or mixed-treatment data were not considered (telbivudine), the manufacturer submission did not contain sufficient data to conduct the indirect comparison, and the agency rejected the drug for listing.

\section{Discussion}

Substantial variability exists in the clinical evidence bases considered for HTA decisions by different agencies, which might be expected given the variability in HTA submission recommendations. ${ }^{8}$ Our findings regarding the nine drugs/indications discussed indicated that the variability in trials included across agencies seemed to be related to what were considered relevant comparators, manufacturer submission of different sets of trials to different agencies, and particular agency selectivity for inclusion or exclusion of certain trials. Agency rejection of clinical trials from consideration or manufacturer exclusion of clinical trials occurred in many cases because of perceived irrelevance of either the dosing regimens of the drug under evaluation or of the comparator, and/or trial population. In most cases, NICE considered the largest number of comparators across each drug reviewed (up to six), with CDR predominantly limiting to one or two and PBAC falling in between. When drugs were recommended for listing, CDR tended to impose restrictions more frequently (six of six positive recommendations, 100\%) than did PBAC (five of eight, 63\%) or NICE (four of seven, 57\%). One potential explanation is that in most cases in which CDR recommended listing the drug 
(five of six positive recommendations, 83\%), the marketing authorization relevant to CDR tended to be the broadest. However, the restrictions recommended by CDR tended to limit use to those same patients ultimately recommended for reimbursement by PBAC and/or NICE.

Most HTA guidelines indicate a preference for direct, head-to-head RCTs as the primary sources of clinical evidence when available ${ }^{8}$ but the guidelines for submissions to PBAC, CDR, and NICE all recognize the need for indirect comparisons of clinical end points to evaluate new drugs against current treatments. ${ }^{8}$ In most PBAC and NICE decisions that we reviewed, indirect comparisons were accepted when there were no apparent head-to-head trial data available.

CDR did not appear to consider any indirect or mixed-treatment comparison data, or did not refer to any such analyses in their published recommendations. This may explain why, for the nine drugs reviewed, CDR considered the greatest number of head-to-head clinical trials among the three agencies by $30 \%$ (CDR 35 trials, NICE 27, PBAC 25). One explanation for this finding could be because manufacturer submissions to CDR include a greater number of direct head-to-head trials. The lack of indirect and/or mixed-treatment comparisons in CDR assessments may have also contributed to this agency's higher overall rate of drug rejection in the selected group of HTAs ( $33 \%$ vs $11 \%$ for PBAC and $22 \%$ for NICE). In the case of natalizumab, CDR specifically did not recommend the drug for listing based on the lack of head-to-head evidence against beta-interferon and glatiramer acetate. In contrast, PBAC and NICE both used indirect and/or mixedtreatment comparisons against these comparators in their assessments and subsequently recommended natalizumab for listing. Therefore, if CDR had considered indirect and/or mixed-treatment evidence for comparison with beta-interferon and glatiramer acetate, this evidence could potentially have changed CDR's decision on natalizumab from that of rejection of reimbursement to one recommending reimbursement. However, upon reconsideration, CDR did accept a restricted listing for natalizumab based mainly on reduction in pricing of the drug.

In the case of telbivudine, a lack of indirect evidence may have contributed to its rejection by both CDR and NICE. The NICE ERG specifically criticized the lack of indirect comparison data against entecavir in the manufacturer submission, despite the existence of several relevant trials that could have been used for the comparison. PBAC did consider indirect evidence using two trials evaluating entecavir versus lamivudine and ultimately recommended listing telbivudine.
While this outcome occurred for only one drug, the lack of use of indirect and/or mixed-treatment comparisons by both CDR and NICE was coincident with the decision to reject drug listing.

CDR submission guidelines for manufacturers indicate consideration of indirect comparisons in drug assessment; however, they suggest that these comparisons may be limited to cases where no head-to-head trials have been conducted versus drugs already available (Canadian Agency for Drugs and Technologies in Health, 2011). ${ }^{13}$ Despite this guidance by CDR, there could potentially be important insights for listing decisions to be captured through indirect comparisons even when direct head-to-head trials exist.

This study confirms and expands upon the prior work of Clement et al and Trueman et al that disparate recommendation decisions across HTA bodies are associated with differences in the clinical evidence base considered. ${ }^{3,9}$ While we were not able to quantify the extent to which dissimilar evidence bases alone contribute to differing agency recommendations, we were able to qualify some specific causes of the differences. As a discipline, the appraisal of evidence by HTA bodies can reflect many factors, including the relevant clinical and economic evidence considered, national and regional differences in drug costs, currently available treatments, and priorities and values of the populations affected..$^{4,5,10-12}$ The extent to which these criteria are applied in practice can be variable across HTA bodies and not always explicitly transparent. ${ }^{14,15}$

An incidental finding of our review was variability in the transparency of evidence used to make HTA decisions across the three HTA agencies included in our analysis. Transparency in the HTA process and the detailed basis on which decisions were made were identified by Drummond and colleagues ${ }^{1}$ as one of the key principles for improved conduct of HTA. Of the HTA decisions for the nine drugs/ indications we reviewed, PBAC decisions were the most transparent of those published by the three agencies in terms of the clinical data considered in the published guidance documents. Transparency meant, for example, that publicly available PBAC guidance documents fully listed all the clinical studies scrutinized by the agency in rendering the reimbursement decision. NICE failed to provide a comprehensive list of all studies considered in its guidance documents in many cases, but this detail was provided in the published manufacturer submissions and ERG reports. CDR recommendations were the least transparent, and in most cases they did not include identification of the key studies considered (although all three agencies listed the number of 
studies that they evaluated). One possible additional advantage of greater transparency for the clinical database used in decision-making would be increased discussion and a better understanding of the strength of the evidence for clinical effectiveness for the reimbursement recommendations for different patient subgroups in different countries. A better understanding of the strength of the evidence for clinical effectiveness for different patient subgroups may allow for more appropriate prescribing of the new drugs.

Our current work furthers the understanding regarding potential reasons for disparate listing recommendations across PBAC, CDR, and NICE for a given subset of drugs/ indications, despite the similar approaches of these agencies in assessing clinical evidence. In the subset of drug decisions reviewed, our analysis specifically points to the key role of using the most relevant clinical comparators, the potential impact of agencies' consideration of direct head-to-head versus indirect and/or mixed-treatment comparison evidence, and the exclusion of key trials in which drugs are not used according to jurisdiction-specific marketing authorization in drug assessments. Because published guidelines from PBAC, CDR, and NICE indicate acceptance of direct and indirect and/or mixed-treatment evidence, it is interesting that in the subset of listing recommendations we reviewed, not one CDR assessment indicated consideration of indirect/ mixed-treatment drug comparisons. These findings highlight the importance that manufacturers not only heed submission guidelines published by HTA agencies but also understand de facto evidence preferences to maximize the potential for listing.

There are a number of limitations in our analysis. Although our findings suggest a correlation between the consideration of only direct drug comparisons by CDR and this agency's low rate of positive listing recommendations relative to PBAC and NICE in the set of decisions analyzed, a causal connection cannot be assumed between these observations. Furthermore, PBAC, CDR, NICE, and other HTA agencies likely do not always incorporate the full extent of decision-making criteria into published HTA guidance (or even the ERG report for NICE decisions), including the full extent of discussions with the manufacturer and confidential price negotiations, which commonly impact reversal of reimbursement recommendations that occur upon manufacturer resubmissions. ${ }^{1,3}$ Given the small sample of HTAs from the three agencies reviewed based on the necessary selection criteria, the full extent to which our findings extend to all decision-making by PBAC, CDR, and NICE is uncertain and does not necessarily apply to other agencies. A follow-up study within the next few years when more HTAs match the selection criteria would be valuable to confirm our findings and to explore any changes in the potential contribution of clinical evidence bases in agency decision-making.

\section{Conclusion}

Our review provides an in-depth analysis of the variability in the clinical evidence bases considered by three different HTA agencies and their associated and/or resulting reimbursement decisions. Themes that emerged to account for differing evidence bases evaluated for the same drugs include a broad-versus-narrow view of the most relevant comparators, exclusion of trials in which the drug under evaluation or a comparator is not used according to its jurisdiction-specific marketing authorization indication, and consideration of direct headto-head versus indirect and/or mixed-treatment comparison. While CDR submission guidelines for manufacturers indicate consideration of indirect comparisons in drug assessment in cases where no head-to-head trials exist versus currently available drugs ${ }^{13}$ there may be greater and more consistent transparency by HTA bodies regarding decision-making criteria, and relative importance of the different aspects of HTA could aid manufacturers in generating and providing an appropriate body of evidence to inform decision-making. Ongoing discussion about HTA harmonization, particularly of clinical data, could also potentially standardize this aspect of the evidence base.

\section{Acknowledgments}

The authors would like to thank Jake Lebiecki (RTI Health Solutions, Manchester, UK) for proofing the technical details of the manuscript. Funding and support for this research was provided by Eli Lilly and Company, who contributed to the design of the study, interpretation of the data, and review of the manuscript.

\section{Disclosure}

The authors declare no conflicts of interest in this work.

\section{References}

1. Drummond MF, Schwartz JS, Jönsson B, et al. Key principles for the improved conduct of health technology assessments for resource allocation decisions. Int J Technol Assess Health Care. 2008;24:244-258.

2. Lexchin J, Mintzes B. Medicine reimbursement recommendations in Canada, Australia, and Scotland. Am J Manag Care. 2008;14:581-588.

3. Clement FM, Harris A, Li JJ, Yong K, Lee KM, Manns BJ. Using effectiveness and cost-effectiveness to make drug coverage decisions. JAMA. 2009;302:1437-1443.

4. Rocchi A, Miller E, Hopkins RB, Goeree R. Common Drug Review recommendations: an evidence base for expectations? Pharmacoeconomics. 2012;30:229-246. 
5. Morgan SG, McMahon M, Mitton NC, et al. Centralized drug review processes in Australia, Canada, New Zealand, and the United Kingdom. Health Aff (Millwood). 2006;25:337-347.

6. Banta D. The development of health technology assessment. Health Policy. 2003;63:121-132.

7. Hutton J, Trueman P, Facey K. Harmonization of evidence requirements for health technology assessment in reimbursement decision making. Int J Technol Assess Health Care. 2008;24:511-517.

8. Mauskopf J, Walter J, Birt J, Bowman L, Copley-Merriman C, Drummond M. Differences among formulary submission guidelines: implications for health technology assessment. Int $J$ Technol Assess Health Care. 2011;27:261-270.

9. Trueman P, Hurry M, Bending M, Hutton J. The feasibility of harmonizing health technology assessments across jurisdictions: a case study of drug eluting stents. Int J Technol Assess Health Care. 2009;25: 455-462.

10. Tappenden P, Brazier J, Ratcliffe J, Chilcott J. A stated preference binary choice experiment to explore NICE decision making. Pharmacoeconomics. 2007;25:685-693.
11. Devlin N, Parkin D. Does NICE have a cost-effectiveness threshold and what other factors influence its decisions? A binary choice analysis. Health Econ. 2004;13:437-452.

12. Harris AH, Hill SR, Chin G, Li JJ, Walkom E. The role of value for money in public insurance coverage decisions for drugs in Australia: a retrospective analysis 1994-2004. Med Decis Making. 2008;28: 713-722.

13. Canadian Agency for Drugs and Technologies inhealth. Available from: hppt://www.cadth.ca. Accessed December 9, 2012.

14. Cleemput I, Neyt M, Thiry N, De Laet C, Leys M. Using threshold values for cost per quality-adjusted life-year gained in healthcare decisions. Int J Technol Assess Health Care. 2011;27:71-76.

15. Golan O, Hansen P, Kaplan G, Tal O. Health technology prioritization: which criteria for prioritizing new technologies and what are their relative weights? Health Policy. 2011;102:126-135. 


\section{Supplementary data \\ PBAC decisions}

Abatacept (Orencia, Bristol-Myers Squibb Pharmaceuticals), rheumatoid arthritis. 2007. Available from: http://www. health.gov.au/internet/main/publishing.nsf/Content/52483 362FE78370ECA2573F5007CA16E/\$File/Abatacept $\% 20$ ORENCIA \%20\%20BMS\%205.1\%20PSD\%20Nov\%20 07\%20FINAL.pdf. Accessed December 9, 2012.

Adalimumab (Humira, Abbott Australasia), psoriasis. 2008. Available from: http://www.health.gov.au/internet/ main/publishing.nsf/Content/7ED276BC00E92383CA257 4EE007A4531/\$File/Adalimumab\%20Final\%20PSD.pdf. Accessed December 9, 2012.

Dabigatran etexilate mesilate (Pradaxa, Boehringer Ingelheim), prevention of thromboembolism following hip or knee replacement. 2009. Available from: http://www.health. gov.au/internet/main/publishing.nsf/Content/586D8D70924 27D7CCA2576CD007F6483/\$File/Dabigatran\%20112009. pdf. Accessed December 9, 2012.

Natalizumab (Tysabri, Biogen Idec Australia), multiple sclerosis. 2007. Available from: http://www.health. gov.au/internet/main/publishing.nsf/Content/B5A97B8C 54125D0FCA2573FB00093EF4/\$File/Natalizumab\%20 TYSABRI\%20Biogen \%20Idec $\% 207.7 \% 20$ PSD $\% 20$ Nov\%2007\%20FINAL.pdf. Accessed December 9, 2012.

Rivaroxaban (Xarelto, Bayer Australia), prevention of thromboembolism following hip or knee replacement. 2009. Available from: http:/www.health.gov.au/internet/main/ publishing.nsf/Content/3F21A90DF2AE6FBBCA2575E1000 65DB1/\$File/Rivaroxaban\%20BAYER\%20PSD\%205-7\%20 2009-03\%20Final.pdf. Accessed December 9, 2012.

Telbivudine (Sebivo, Novartis Pharmaceuticals Australia), hepatitis B. 2008. Available from: http://www.health.gov.au/ internet/main/publishing.nsf/Content/6405634DE0F751F0C A25747400114A19/\$File/pbac-psd-telbivudine-mar08.pdf. Accessed December 9, 2012.

Tenofovir disoproxil fumarate (Viread, Gilead Sciences), hepatitis B. 2008. Available from: http://www.health.gov.au/ internet/main/publishing.nsf/Content/EFCF57BA49355CE1 CA25756D001DD1C7/\$File/pbac-psd-tenofovir-nov08.pdf. Accessed December 9, 2012.

Ustekinumab (Stelara, Janssen-Cilag), psoriasis. 2009. Available from: http://www.health.gov.au/internet/main/ publishing.nsf/Content/83DE850311C895EFCA2576D2 0081008E/\$File/Ustekinumab\%20112009.pdf. Accessed December 9, 2012.

Varenicline tartrate (Champix, Pfizer Australia), smoking cessation. 2007. Available from: http://www.health.gov.
au/internet/main/publishing.nsf/Content/FC5F6229F 06C715ECA257379002422D3/\$File/Varenicline $\% 20$ Champix\%20PSD\%205.14\%20Pfizer\%20FINAL.pdf. Accessed December 9, 2012.

\section{CDR decisions}

Canadian Agency for Drugs and Technologies in Health. Abatacept (Orencia, Bristol-Myers Squibb Canada), rheumatoid arthritis. 2007. Available from: http://www.cadth.ca/ media/cdr/complete/cdr_complete_Orencia_June-27-2007. pdf. Accessed December 9, 2012.

Canadian Agency for Drugs and Technologies in Health. Adalimumab (Humira, Abbott Laboratories), psoriasis. 2008. Available from: http://www.cadth.ca/media/cdr/ complete/cdr_complete_Humira-Psoriasis_October_2008. pdf. Accessed December 9, 2012.

Canadian Agency for Drugs and Technologies in Health. Dabigatran etexilate (Pradax, Boehringer Ingelheim Canada Ltd), prevention of venous thrombosis in hip or knee replacement surgery. 2009. Available from: http://www.cadth.ca/ media/cdr/complete/cdr_complete_Pradax_March-3-2009. pdf. Accessed December 9, 2012.

Canadian Agency for Drugs and Technologies in Health. Natalizumab (Tysabri, Biogen Idec Canada), multiple sclerosis. 2007. Available from: http://www.cadth.ca/media/ cdr/complete/cdr_complete_Tysabri_e_April-26-2007.pdf. Accessed December 9, 2012.

Canadian Agency for Drugs and Technologies in Health. Rivaroxaban (Xarelto, Bayer), prevention of venous thrombosis in hip or knee replacement surgery. 2008. Available from: http://www.cadth.ca/media/cdr/complete/cdr_xarelto_ complete-dec17-08.pdf. Accessed December 9, 2012.

Canadian Agency for Drugs and Technologies in Health. Telbivudine (Sebivo, Novartis Pharmaceuticals Canada), hepatitis B infection. 2007. Available from: http://www. cadth.ca/media/cdr/complete/cdr_complete_Sebivo_ September-26-2007.pdf. Accessed December 9, 2012.

Canadian Agency for Drugs and Technologies in Health. Tenofovir disoproxil fumarate (Viread, Gilead Sciences Canada), hepatitis B infection. 2009. Available from: http://www.cadth.ca/media/cdr/complete/cdr_ complete_Viread-HBV_March-18-2009.pdf. Accessed December 9, 2012.

Canadian Agency for Drugs and Technologies in Health. Ustekinumab (Stelara, Janssen-Ortho), psoriasis. 2009. Available from: http://www.cadth.ca/media/cdr/ complete/cdr_complete_Stelara_June-17-2009.pdf. Accessed December 9, 2012. 
Canadian Agency for Drugs and Technologies in Health. Varenicline tartrate (Champix, Pfizer Canada), smoking cessation. 2007. Available from: http://www.cadth.ca/media/ cdr/complete/cdr_complete_Champix_August-16-07.pdf. Accessed December 9, 2012.

\section{NICE decisions}

Abatacept for the treatment of rheumatoid arthritis. 2007. Available from: http://www.nice.org.uk/nicemedia/ live/11720/37928/37928.pdf. Accessed December 9, 2012.

Adalimumab for the treatment of adults with psoriasis. 2008. Available from: http://www.nice.org.uk/nicemedia/ live/12007/41002/41002.pdf. Accessed December 9, 2012.

Dabigatran etexilate for the prevention of venous thromboembolism after hip or knee replacement surgery in adults. 2011. Available from: http://www.nice.org.uk/nicemedia/ live/12059/42032/42032.pdf. Accessed December 9, 2012.

Natalizumab for the treatment of adults with highly active relapsing-remitting multiple sclerosis. 2010. Available from: http://www.nice.org.uk/nicemedia/live/11822/36136/36136. pdf. Accessed December 9, 2012.

Rivaroxaban for the prevention of venous thromboembolism after total hip or total knee replacement in adults. 2012. Available from: http://www.nice.org.uk/nicemedia/ live/12133/43811/43811.pdf. Accessed December 9, 2012.

Telbivudine for the treatment of chronic hepatitis B. 2009. Available from: http://www.nice.org.uk/nicemedia/ live/12052/41680/41680.pdf. Accessed December 9, 2012.

Tenofovir disoproxil for the treatment of chronic hepatitis B. 2012. Available from: http://www.nice.org.uk/nicemedia/ pdf/TA173Guidance.pdf. Accessed December 9, 2012.

Ustekinumab for the treatment of adults with moderate to severe psoriasis. 2010. Available from: http://www.nice. org.uk/nicemedia/live/12235/45461/45461.pdf. Accessed December 9, 2012.

Varenicline for smoking cessation. 2010. Available from: http://www.nice.org.uk/nicemedia/live/11809/35940/35940. pdf. Accessed December 9, 2012.

\section{NICE Evidence Review Group reports}

Hartwell D, Jones J, Harris P, Cooper K. Telbivudine as treatment for chronic hepatitis B. 2008. Available from: http:// www.nice.org.uk/nicemedia/live/11834/40321/40321.pdf. Accessed December 9, 2012.

Hind D, Tappenden P, Peters J, Kenjegalieva K. Varenicline for smoking cessation: a single technology appraisal. 2007. Available from: http://www.nice.org.uk/nicemedia/ live/11718/35924/35924.pdf. Accessed December 9, 2012.
Holmes M, Carroll C, Papaioannou D. Dabigatran etexilate for the prevention of venous thromboembolism in patients undergoing elective hip and knee surgery: a single technology appraisal. 2008. Available from: http://www.nice. org.uk/nicemedia/live/11939/41383/41383.pdf. Accessed December 9, 2012.

Jones J, Colquitt J, Shepherd J, Harris P, Cooper K. Tenofovir disoproxil fumarate for the treatment of chronic hepatitis B. 2009. Available from: http://www.nice.org. uk/nicemedia/live/12024/43468/43468.pdf. Accessed December 9, 2012.

Lloyd Jones M, Stevenson M, Stevens J, Sutton A. Abatacept for the treatment of rheumatoid arthritis after the failure of conventional disease-modifying anti-rheumatic drugs. 2011. Available from: http://www.nice.org.uk/ nicemedia/live/13137/53814/53814.pdf. Accessed December 9, 2012.

National Institute for Health and Clinical Excellence Evidence Review Group. Ustekinumab for the treatment of moderate to severe psoriasis. 2009. Available from: http:// www.nice.org.uk/nicemedia/live/12038/44213/44213.pdf. Accessed December 9, 2012.

Peninsula Technology Assessment Group. The effectiveness and cost-effectiveness of natalizumab for multiple sclerosis: an evidence review of the submission from Biogen. 2007. Available from: http://www.nice.org.uk/nicemedia/ live/11701/35004/35004.pdf. Accessed December 9, 2012.

School of Health and Related Research (ScHARR), the University of Sheffield. Rivaroxaban for the prevention of venous thromboembolism. Available from: http://www.nice. org.uk/nicemedia/live/12026/43711/43711.pdf. Accessed December 9, 2012.

Turner D, Picot J, Cooper K, Loveman E. Adalimumab for the treatment of psoriasis. 2007. Available from: http:// www.nice.org.uk/nicemedia/live/11811/39105/39105.pdf. Accessed December 9, 2012.

\section{NICE manufacturer submissions}

Abbott Laboratories. Adalimumab (Humira) for the treatment of moderate to severe plaque psoriasis. 2007. Available from: http://www.nice.org.uk/nicemedia/live/11811/39114/39114. pdf. Accessed December 9, 2012.

Bayer Healthcare. Single technology appraisal of rivaroxaban (Xarelto) for the prevention of venous thromboembolism (VTE) in adult patients undergoing elective hip or knee replacement surgery. 2008. Available from: http:// www.nice.org.uk/nicemedia/live/12026/43495/43495.pdf. Accessed December 9, 2012. 
Biogen Idec. Natalizumab (Tysabri) for the treatment of adults with highly active relapsing remitting multiple sclerosis. Available from: http://www.nice.org.uk/nicemedia/ live/11701/36109/36109.pdf. Accessed December 9, 2012.

Biogen Idec. Natalizumab (Tysabri) for the treatment of adults with highly active relapsing remitting multiple sclerosis: addendum. 2006. Available from: http://www.nice. org.uk/nicemedia/live/11701/36110/36110.pdf. Accessed December 9, 2012.

Boehringer Ingelheim. Dabigatran etexilate for the prevention of venous thromboembolism after hip or knee replacement surgery in adults. 2008. Available from: http:// www.nice.org.uk/nicemedia/live/11939/41391/41391.pdf. Accessed December 9, 2012.

Bristol-Myers Squibb. Abatacept for the treatment of rheumatoid arthritis after the failure of conventional diseasemodifying anti-rheumatic drugs. 2010. Available from: http:// www.nice.org.uk/nicemedia/live/13137/53828/53828.pdf. Accessed December 9, 2012.

Gilead. Tenofovir (Viread) for the treatment of chronic hepatitis B. 2008. Available from: http://www.nice.org.uk/ nicemedia/live/12024/43472/43472.pdf. Accessed December 9, 2012.

Janssen-Cilag. Ustekinumab (Stelara) for the treatment of moderate to severe plaque psoriasis in England and Wales. 2009. Available from: http://www.nice.org. uk/nicemedia/live/12038/44222/44222.pdf. Accessed December 9, 2012.

Novartis Pharmaceuticals UK. Sebivo (telbivudine). Available from: http://www.nice.org.uk/nicemedia/ live/11834/40324/40324.pdf. Accessed December 9, 2012.

Pfizer UK. Varenicline. 2007. Available from: http:// www.nice.org.uk/nicemedia/live/11718/35932/35932.pdf. Accessed December 9, 2012.

\section{Canadian marketing authorizations}

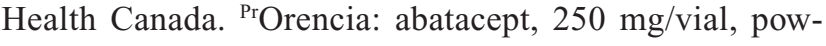
der for solution. 2007. Available from: http://www.hc-sc. gc.ca/dhp-mps/alt_formats/hpfb-dgpsa/pdf/prodpharma/ sbd_smd_2007_orencia_098531-eng.pdf. Accessed December 9, 2012.

Health Canada. ${ }^{\text {PrPradax: dabigatran etexilate, } 75 \mathrm{mg} \text { and }}$ $110 \mathrm{mg}$ capsules. 2008. Available from: http://www.hc-sc. gc.ca/dhp-mps/alt_formats/hpfb-dgpsa/pdf/prodpharma/ sbd_smd_2008_pradax_114887-eng.pdf. Accessed December 9, 2012.

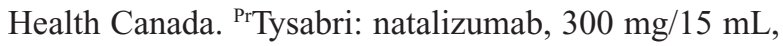
solution. 2007. Available from: http://www.hc-sc.gc.ca/ dhp-mps/alt_formats/hpfb-dgpsa/pdf/prodpharma/ sbd_smd_2007_tysabri_093001-eng.pdf. Accessed December 9, 2012.

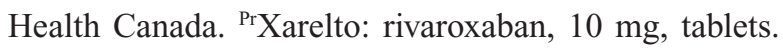
2009. Available from: http://www.hc-sc.gc.ca/dhp-mps/ alt_formats/hpfb-dgpsa/pdf/prodpharma/sbd_smd_2009_ xarelto_119111-eng.pdf. Accessed December 9, 2012.

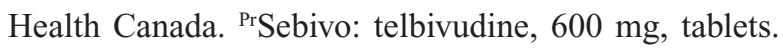
2008. Available from: http://www.hc-sc.gc.ca/dhp-mps/ alt_formats/hpfb-dgpsa/pdf/prodpharma/sbd_smd_2008_ sebivo_104469-eng.pdf. Accessed December 9, 2012.

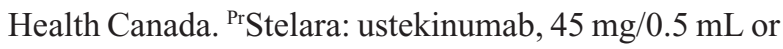
$90 \mathrm{mg} / 1.0 \mathrm{~mL}$, solution. 2009. Available from: http:// www.hc-sc.gc.ca/dhp-mps/alt_formats/hpfb-dgpsa/ pdf/prodpharma/sbd_smd_2009_stelara_114272-eng.pdf. Accessed December 9, 2012.

Health Canada. ${ }^{\mathrm{Pr}} \mathrm{Champix}$ : varenicline tartrate, $0.5 \mathrm{mg}$ and $1.0 \mathrm{mg}$ tablets. 2008. Available from: http://www.hc-sc. gc.ca/dhp-mps/alt_formats/hpfb-dgpsa/pdf/prodpharma/ sbd_smd_2008_champix_104007-eng.pdf. Accessed December 9, 2012. 


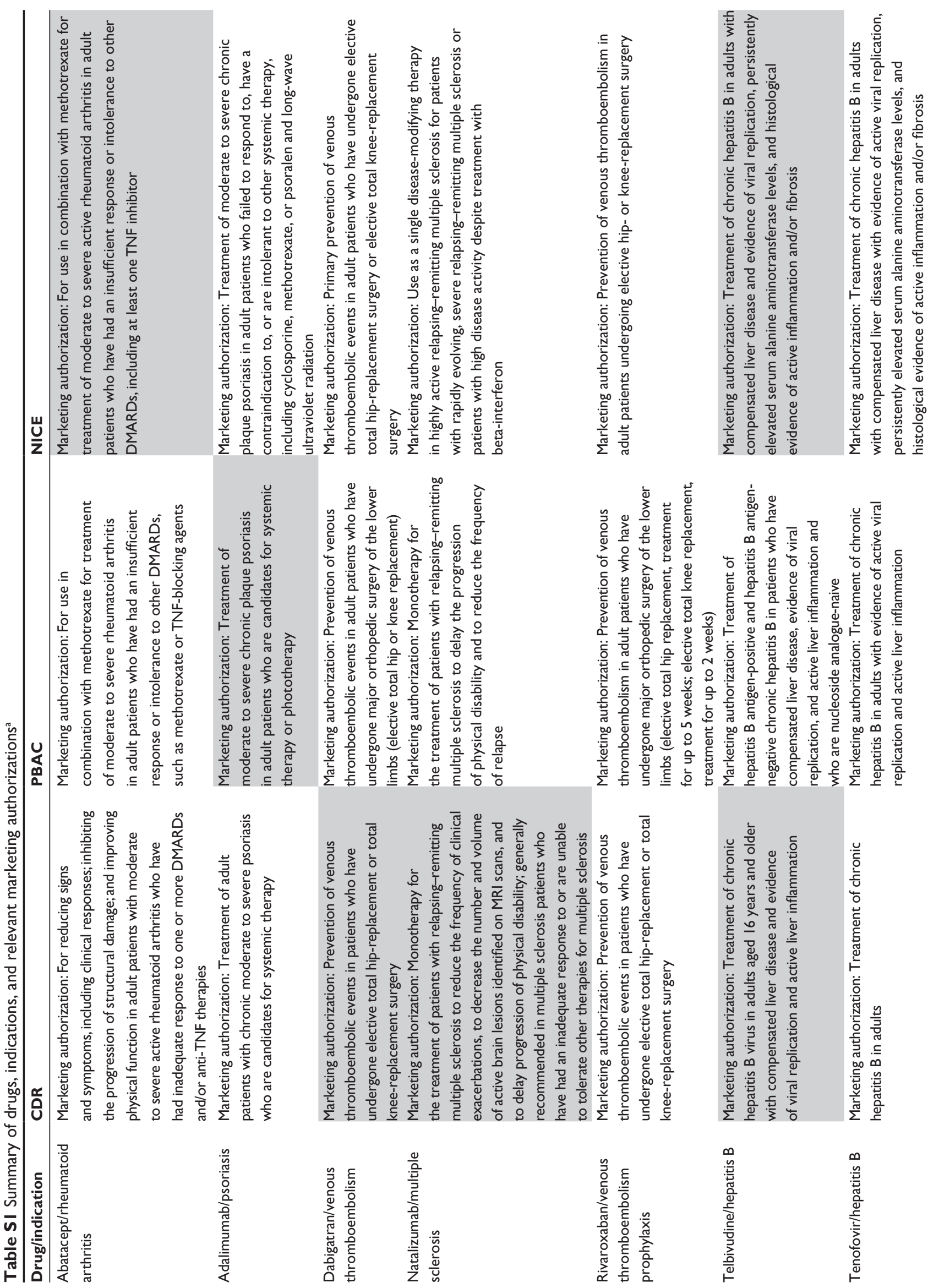




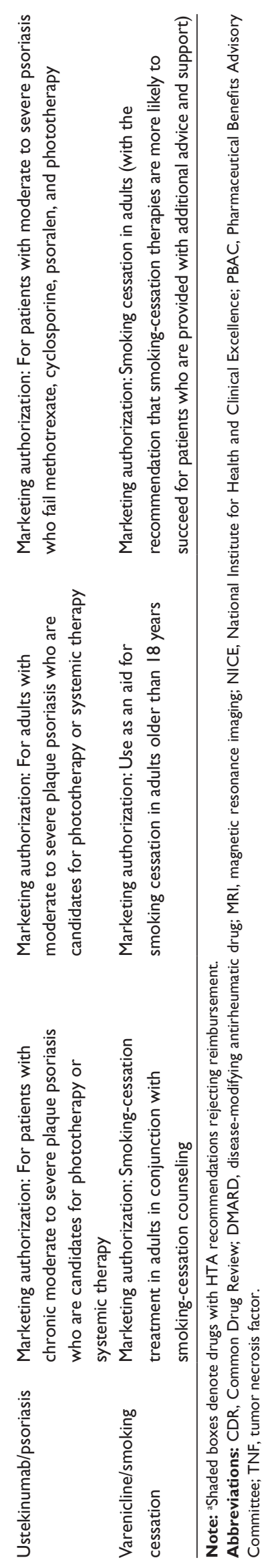




\section{Publish your work in this journal}

ClinicoEconomics \& Outcomes Research is an international, peerreviewed open-access journal focusing on Health Technology Assessment, Pharmacoeconomics and Outcomes Research in the areas of diagnosis, medical devices, and clinical, surgical and pharmacological intervention. The economic impact of health policy and health systems organization also constitute important areas of coverage. The manuscript management system is completely online and includes a very quick and fair peer-review system, which is all easy to use. Visit http://www.dovepress.com/testimonials.php to read real quotes from published authors.

Submit your manuscript here: http://www.dovepress.com/clinicoeconomics-and-outcomes-research-journal 